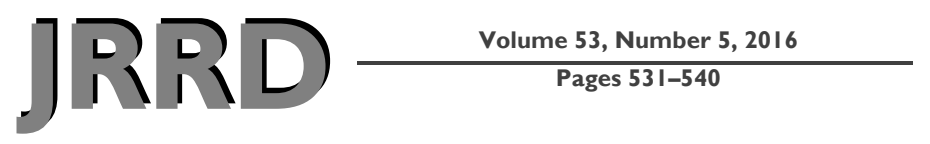

\title{
Scoping review of mobility scooter-related research studies
}

\author{
W. Ben Mortenson, PhD, MSc, BScOT, OT; ${ }^{1-2 *}{\text { Jenny Kim, } \text { BSc }^{2}}^{2}$ \\ ${ }^{1}$ Department of Occupational Science and Occupational Therapy, University of British Columbia, Vancouver, Canada; \\ International Collaboration on Repair Discoveries, Vancouver, Canada; and Rehabilitation Research Program, \\ Vancouver Coastal Health Research Institute, Vancouver, Canada; ${ }^{2}$ GF Strong Rehabilitation Research Program, \\ Vancouver, Canada
}

\begin{abstract}
Mobility scooters are three- or four-wheeled power mobility devices regularly used by people who have difficulty ambulating. They also differ from power wheelchairs in terms of their driving controls, programmability, seating, and mounting method. Given their growing popularity and anecdotal concerns around their use, a scoping review was undertaken to identify empirical research about mobility scooters and to analyze their study design and purpose. Data sources included MedLINE, Cumulative Index to Nursing and Allied Health Literature, Embase, and PsychINFO. Thirty-two studies met the inclusion criteria. Most studies were descriptive in nature and reported information about scooter users' demographics, scooter-related activities, and accidents. The most common study design was a pre- and postintervention followed by a cross-sectional survey and retrospective review. Despite the increasing use of mobility scooters, surprisingly little scooterrelated research has been conducted. Given the nature of most of the research in this area, further empirical evidence is needed to develop a better understanding about the frequency and causes of scooter accidents and the efficacy of interventions to improve users' skills, mobility, and safety.
\end{abstract}

Key words: accidents, incidents, mobility, participation, powered mobility, safety, scooters, scoping review, survey, training.

\section{INTRODUCTION}

Mobility scooters are typically used to facilitate community mobility among individuals with mobility limitations. Mobility scooters differ from power wheelchairs in terms of (1) control (tiller versus joy stick or alternate access), (2) programmability (the control parameters of power wheelchairs can be finely adjusted [e.g., turning acceleration and deceleration], whereas scooters can only have their overall speed adjusted), (3) seating (power wheelchairs have more custom seating options available, whereas scooters generally come equipped with a generic captain's seat), and (4) mounting method (scooter seating can swivel). Mobility scooters tend to be more affordable than power wheelchairs. Given their larger turning radii, scooters are frequently used outside the home to facilitate activities such as shopping, banking, and medical appointments [1]. Because most scooter users have problems ambulating, they frequently use alternative devices inside (e.g., canes or manual wheelchairs) [2].

The prevalence of scooter use varies considerably from country to country. In 2006, it was estimated that there were more than 60,000 scooter users in Canada [3], and in 1998, it was estimated that there were 142,000 scooter users in the United States [4]. Given the dates of the previous North American surveys, they likely underestimate the current prevalence. In contrast, a recent national survey in Australia, a country that has approximately 67 percent of the Canadian population and 7 percent of the

\footnotetext{
Abbreviation: RCT $=$ randomized controlled trial.

*Address all correspondence to $\mathrm{W}$. Ben Mortenson, PhD, MSc, BScOT, OT; T-325-2211 Wesbrook Mall, Vancouver, BC, Canada V6T 2B5; 604-822-7392; fax: 604-822-7624.

Email: ben.mortenson@ubc.ca http://dx.doi.org/10.1682/JRRD.2015.05.0084
} 
U.S. population, found that there were approximately 231,000 scooter users (i.e., 13 out of every 1,000 adults owned a scooter) [5].

Despite their size and potential issues with accessibility, scooters may be preferred over other devices. Scooters may be perceived as less stigmatizing than power wheelchairs, which are often used by individuals with greater functional impairments [6]. However, some people may have difficulty obtaining funding for a scooter if it is used to facilitate outdoor mobility [7], which may not be deemed "medically necessary" [8].

Scooter drivers are frequently portrayed negatively in the media. They are often described as a threat; for example, "Seaside town cracks down on the menace of speeding mobility scooters." Concerns about the age of scooter drivers are frequently emphasized, such as "Beware of seniors driving scooters." ${ }^{\dagger}$ Injuries and fatalities related to scooters are commonly reported in the news. Because of the increasing prevalence of mobility scooters, mandatory training/licensing has been suggested in a variety of countries including Australia, the United Kingdom, and Canada. Some jurisdictions require some types of scooters to be registered (see Appendix 1, available online only, for more information about scoot-ers in the media).

Given the prevalence and importance of mobility scooters and potential concerns about their use, a scoping review was conducted to identify empirical research on mobility scooters. Specifically, the scoping review sought to identify and categorize recent published research about mobility scooters. This included both white and gray literature (i.e., research available in peerreviewed journals versus research that is available outside of academic publishing channels, such as on government Web sites and in conference proceedings).

* Cusack B. Seaside town cracks down on the menace of speeding mobility scooters. Mirror [Internet]. 2014 October 28 [cited 2015 May 15; Weird News: [about 1 screen]. Available from: http:// www.miror.co.uk/news/weird-news/seaside-town-cracks-down-menace-4524748

${ }^{\dagger}$ McKinnell J. Beware of seniors driving scooters. Maclean's [Internet]. 2009 November 19 [cited 2015 May 15]; Culture:[10 paragraphs]. Available from: http://macleans.ca/culture/beware-ofseniors-driving-scooters

\section{METHODS}

In comparison to systematic reviews, scoping reviews typically have a broader focus and tend not to assess the quality of included studies [9]. Though not specific to scoping reviews, we used the Preferred Reporting Items for Systematic Reviews and Meta-Analyses guidelines [10] to facilitate how the review content was reported in this article.

\section{Inclusion Criteria}

The literature search was performed by trained research assistants. The criterion for inclusion was empirical research that had relevant applications to scooter users. Studies were excluded if (1) scooter user data were combined with other mobility device user data, (2) there was no scooter-specific analysis of data, or (3) less than 74 percent of the study sample were scooter users in mixed mobility device studies. The references of relevant studies were reviewed to identify other potential studies for inclusion. Systematic reviews were also used to identify potential primary studies.

\section{Search Methods}

As outlined in the Table, a variety of database-specific Medical Subject Headings were combined with the key word searches "scooter" or "power mobility" to identify relevant studies. Four electronic databases were used to identify studies: MedLINE, Cumulative Index to Nursing and Allied Health Literature, Embase, and PsychINFO. The search was limited to articles published between January 2000 and April 2015. The term "mobility scooter” was used in Google to identify gray literature in this area. In

Table.

Database-specific Medical Subject Headings search strategies.

MedLINE:

[Wheelchair or self-help devices or dependent ambulation or mobility limitation] and [electric power supplies or electricity]

Cumulative Index to Nursing and Allied Health Literature:

Ambulation aids or wheelchairs, powered or wheelchairs

Embase:

[Electric wheelchair or powered wheelchair] or [walking difficulty or wheelchair or self help or physical mobility or assistive technology] and [electricity or electrical equipment]

PsychINFO:

Mobility aids or assistive technology or technology or medical therapeutic devices or physical mobility 
Google Scholar, the names of lead authors from the included studies were searched to identify articles that may have been missed in the database searches. Conference proceedings from the last $10 \mathrm{yr}$ of the International Seating Symposium and Rehabilitation Engineering and Assistive Technology Society of North America were hand searched (2005-2014).

Titles and abstracts of the articles from the initial search were reviewed by the study research assistants to remove irrelevant or duplicate studies. The remaining studies were retrieved, and a decision for inclusion was made based on review by the authors. Information on the study design, methodology, findings, concluding points, limitations, and study location of included studies was abstracted into a table of evidence. Content analysis was conducted to identify the research focus of included studies [11].

\section{RESULTS}

As noted in the Figure, the search strategy identified 756 articles (from 1,204 articles after duplicates were removed). After review of the title or abstract, 710 articles were excluded. Of the remaining 46 articles, 28 were included after a full review. Three additional articles were identified from the references of included studies, and one additional article was identified from a Google search of the authors of included studies.

\section{Research Designs}

The search strategy identified 32 relevant studies for the scoping review. As described in the method column of Appendix 2 (available online only), the most common research method was an intervention followed by a survey and a retrospective review. Using predominantly preand postintervention designs, 9 intervention studies explored the effects of scooter training on driver competency and examined scooter provision associated outcomes. Retrospective data reviews analyzed previously collected data on accident statistics and demographic information about scooter users. Of the 32 included studies, 12 designed a study-specific questionnaire either with the help of a research ethics board, modified from other validated measures, or extracted from literature searches.

\section{Research Topics}

Appendix 2 is divided into subsections by main topic (i.e., Description of Users/Activities/Accidents, Accident Statistics, Scooter Training, Other Intervention Outcomes, User Experiences, Prescription/Service Delivery/Provision, Environmental Issues). Approximately a third of the included papers were descriptive studies that presented quantitative data about scooter user demographics, descriptions of activities users performed with their scooters, and frequency of scooter-related accidents [1,5,12-19]. For example, a retrospective review of data from the Veterans Health Administration found that Caucasians were more likely to receive mobility scooters in comparison to other ethnicities [12]. The top reported activities facilitated by mobility scooters included going for rides, shopping, and attending medical appointments [1,13-14].

A wide range of accident rates was described [2023]; however, it should also be noted that the definition of accident varied considerably. On the low end, as part of a randomized controlled trial (RCT) by Hoenig et al. [24], which involved data collection at 1 and 3 mo following scooter provision, an accident rate of 1.54 per person per year was reported. In this study, this figure included injury and noninjury accidents. At the high end, an Australian survey that asked about the occurrence of scooter-related incidents reported a 5 percent accident rate on every trip (with an average of 5.8 trips per week; this would be extrapolated to 15 accidents per person per year [5]). In this study, only injury-producing incidents were counted. Similarly, several retrospective review studies described accident rates as injury-related incidents and collected the data through hospitalization and emergency room databases and fatality records [20-21].

The outcomes of scooter provision were generally positive [24-29]. The RCT by Hoenig et al. found that receipt of a scooter did not lead to deconditioning among individuals with arthritis [24]. A pre- and postintervention study by Samuelsson and Wressle found many participants had a significant positive change in activity participation and social participation [25]. Similarly, a pre- and postintervention study by Sund et al. found that following scooter provision, there was an increase in frequency of grocery shopping and going for a walk/ride, and many mobility-related activities became easier (e.g., shopping, posting letters, going to the bank) [26]. Another pre- and postintervention study by Hagberg et al. indicated scooters were cost-effective in that they 

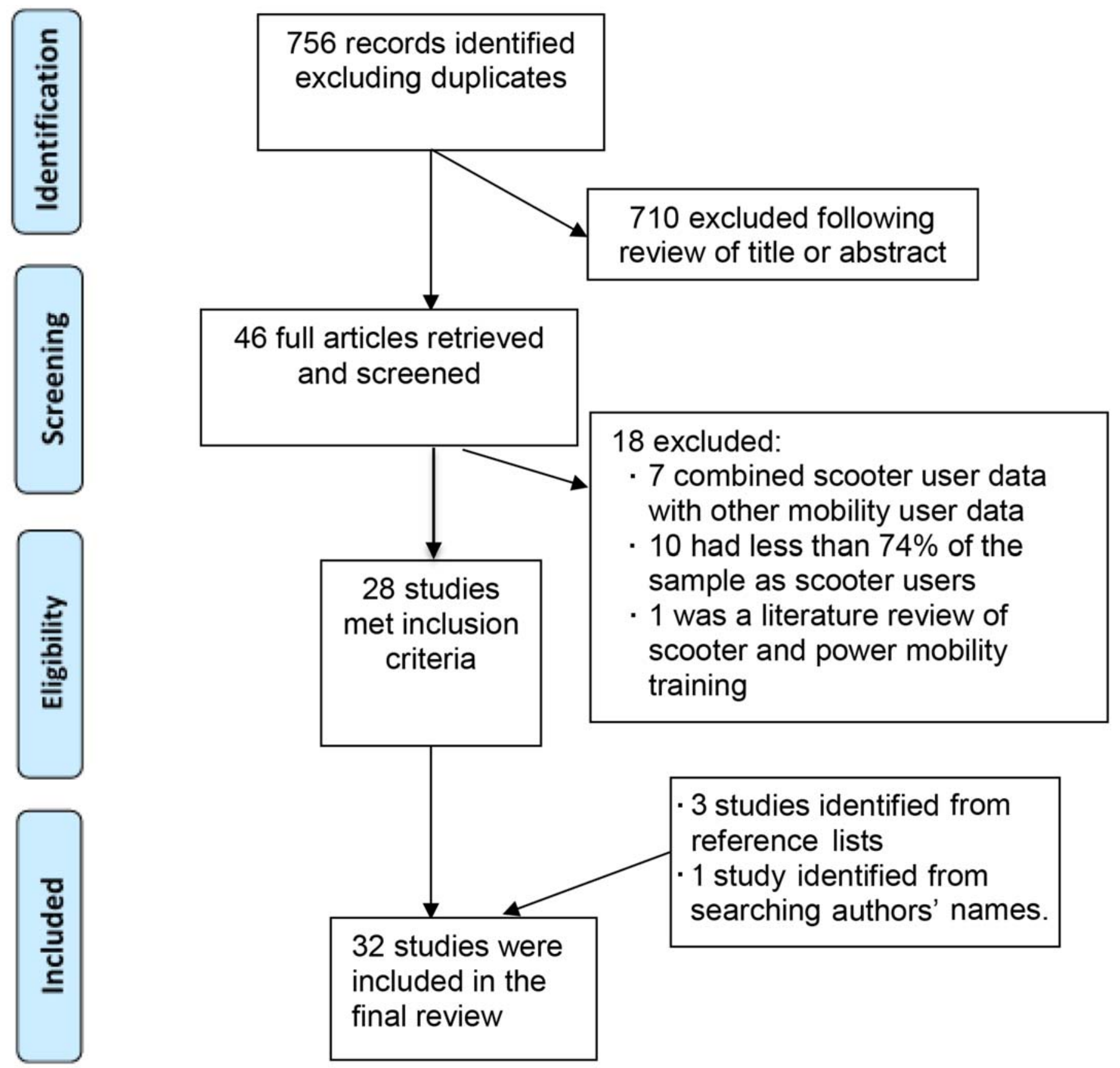

Figure.

Flow diagram of study inclusion.

decreased transport costs by 67 percent and decreased caregiver time requirements by 72 percent [27].

Although scooter training has been recommended to build skills and increase confidence [30], the prevalence of scooter training was low and the outcomes were equivocal [30-33]. Two studies reported that approximately a quarter of scooter users received safety training $[5,30]$. An RCT with 10 participants by Jannink et al. indicated there was no significant difference in scooter driving performance between participants who received "conventional scooter training" twice a week for 5 wk and participants who received conventional training supplemented with a 
virtual simulation program for the same duration of time [31]. In contrast, an RCT by Niv et al. demonstrated a significant improvement in driving skills for participants who received metacognitive training, including on-road driving practice with occupational therapy intervention, compared with participants who received computerized cognitive training alone [32]. Similarly, a cohort study by Nitz found an improvement in scooter driving skills following repetition of the same assessment on three separate occasions, indicating practice contributes to greater driving proficiency [33].

Other research addressed a wide scope of topics. Qualitative studies collected perceptions of user experiences with scooter use [34-35] and stakeholders' perceptions of prescription [36-37]. These studies identified common concerns around scooter maintenance and accessibility and the prescription/service delivery process. Research on product testing indicated mobility scooters were not designed to maneuver in U.S. and Canadian buildings (based on building standards) [3839] and did not meet the American National Standards Institute/Rehabilitation Engineering and Assistive Technology Society of North America wheelchair standards [40]. One study aimed to develop a set of guidelines for the prescription of mobility scooters for individuals with brain or spinal cord injury [41].

\section{DISCUSSION}

This is the first scoping review to identify scooterrelated empirical studies. Overall, there appears to be limited research on mobility scooters. This may be because of the lack of professional involvement in device prescription and service-delivery processes [5], which may make scooter-related research less important among clinicians. However, of the 32 included studies, 7 were published from 2000 to 2007 and 25 were published from 2008 to 2015, which indicates there may be increasing research in this area.

The study designs and topics of the studies reflect the relative novelty of this technology. The majority of studies were descriptive in nature, using survey data or medical records to characterize users [5,13,17-18], identify reasons for use [1,13], document accidents [5,19-21,23], describe device cost and funding [17-18], and explore training [30]. A few studies used qualitative interviews or focus groups to explore users' perceptions of these devices [34-35] or prescription services [36-37]. Several studies tested the stability, handling characteristics, and turning radii of specific scooters in relationship to accessibility or design standards [38-40]. An interest in outcomes was also observed as several pre- and postintervention studies without a control group evaluated outcomes after scooter provision/receipt [15,23,25-27,42]. Only a few studies used more rigorous experimental designs (with a control group) to study the effects of training [31-32] or device provision. Thus, the level of evidence in this area is relatively low.

Given that many studies used nonrepresentative samples, the results are difficult to generalize. For example, a descriptive study included equal numbers of males and females with a mean age of 78 yr old [13], whereas a cohort study by Nitz had a sample with 22 percent men and a mean age of $34 \mathrm{yr}$ [33]. In contrast, one of the few surveys to include a representative sample reported the median age of scooter users in Australia was $60 \mathrm{yr}$ of age [5].

Given the descriptive nature of many studies, causality is difficult to infer. For example, although the study by Hubbard et al. suggested Caucasians were more likely than other ethnicities to receive scooters from the Veterans Health Administration, it is not known whether this is related to discrimination or whether it is a result of other unmeasured confounders [12]. Similarly, a cross-sectional survey by Brandt et al. found a negative correlation between the age of participants and the likelihood of mobility use for prioritized activities; this may be a result of age-related changes or reflect a possible cohort effect [1]. With that caveat in mind, looking across descriptive studies, some consistent findings were evident. Users consistently reported that these mobility devices enabled daily activities and social participation [1,14] and increased feelings of independence [1,13], which emphasizes the perceived importance of scooters.

Looking specifically at social participation, most studies indicated that scooters made participation easier $[26,28]$ or improved users' perceived ability to participate [25]. However, the only study to look at changes in frequency of participation found users experienced significant changes in only a small number of activities [26] and did not begin new activities [26]. Similar results have been found with the introduction of pushrim-activated power-assist wheels for manual wheelchair users [42]. The importance of making activity easier should not be overlooked, however, given the mobility burden that many assistive device users encounter. For example, 
these users may need to travel substantially further than those who can ambulate, because building guidelines generally require only one accessible entrance [43].

Most of the pre- and postintervention studies found that scooter provision was positive in terms of improved independence [28], social engagement [25-26], and costeffectiveness [25,27]. However, without a control group, a variety of other reasons may have explained these findings, including maturation (e.g., the finding may reflect natural changes over time) and selection bias. Furthermore, most of these studies had a relatively short period of follow-up (e.g., 3-4 mo), with the exception of studies by Löfqvist et al. [28] and Sund et al. [26], so the longer-term effects of scooter provision are less well known.

It is difficult to compare the accident rates between scooter users and users of other mobility devices because of differences in the way accidents are defined and reported. Studies of wheelchair users have reported annual injury frequencies of 5 to 18 percent [44-46]. These rates are far below those described for scooter users. Accident data from several studies reported the incidence rate as a percentage of the study sample $[15,17]$. In contrast, accident rates collected retrospectively through hospitalization and fatality data reported absolute numbers and annual percentage increase [20], which makes it difficult to compare findings across studies. The lack of research on scooter-related accidents suggests an inadequacy of the consumer safety system. Relying on hospital statistics likely underestimates the number of accidents, because only the most serious require admission, and causation may be difficult to determine. However, self-report statistics likely suffer from both recall and social desirability biases, which may affect their credibility.

Few scooter users report receiving any training. This finding is consistent with studies of people who use other mobility devices; 18 percent of manual wheelchair users received any formalized training [47], and 19 percent of power wheelchair users received more than $30 \mathrm{~min}$ of training [48]. The shortages in training may stem from a lack of professional advice and education and the complexity of the prescription process [37].

There remains an additional question about the effectiveness of scooter training. The two RCTs about scooter training [31-32] were quite small in scope, so they have been underpowered in terms of sample size. The outcome measures used to evaluate scooter driving ability may also have affected the ability of these studies to detect change.
For example, the retest reliability and construct validity of the Functional Evaluation Rating Scale used in the study by Jannink et al. [31] are unknown.

\section{Future Directions}

The findings from this scoping review suggest a number of potential areas for future research. Surveys that include representative samples would be beneficial to identify not only typical scooter users, but also those who perceive they need but do not have a scooter-an approach that has been followed as part of the Canadian Participation and Activity Limitations Survey [3]. Differentiating between what people have versus what they need would be helpful in understanding what effect funding policies have (i.e., are people who need scooters getting them?) and could also be used for better health service delivery planning. To compare accident data for mobility scooters more effectively, more consistent definitions that provide a clear distinction between injurious and noninjurious accidents should be used. An accurate understanding of mobility-related accidents would better inform public policy in this area, especially in terms of the need for training programs or potential for licensing. Experimental studies using validated measures are needed to evaluate the outcomes produced by scooter training and provision. These outcomes should include not only scooter skills, but also accidents, mobility, participation, and cost-effectiveness. Additional studies could use tracking technologies, such as GPS, to provide more quantitative information on the places scooter users go, the frequency of their trips, and the distances that they travel. Qualitative interviews could then be used to explore user activities in those locations. Finally, additional research is also needed to better understand the social and physical barriers that scooter users experience and to develop strategies to address these challenges.

\section{Limitations}

Three main limitations of the review should be noted. First, it was limited to studies published since 2000. Although this potentially excluded some studies, our review of the references of included studies did not reveal any earlier scooter-related studies that met our inclusion criteria. Furthermore, studies published before this time would have been quite dated, given changes in the technology and improvements in accessibility [2]. Second, given the challenges of searching in the gray literature, relevant unpublished studies may have been 
missed. Third, there was some subjectivity about which studies would be included in the review; however, the criteria were well developed and operationalized, so it is expected others would make similar decisions.

\section{CONCLUSIONS}

Empirical research on mobility scooters was collected and summarized in terms of the study design and methods. Pre- and postinterventions without a control group were the most common study design, followed by crosssectional surveys and retrospective reviews. Most studies were descriptive in nature and provided information about driver demographics, scooter activities performed, and scooter-related accidents. Concerns were raised about the barriers to scooter use including the service delivery process and accessibility. Given the limited empirical knowledge currently available, further research is needed in this area to understand better how to facilitate scooter use and improve user outcomes.

\section{ACKNOWLEDGMENTS}

\section{Author Contributions:}

Study design: W. B. Mortenson, J. Kim.

Data collection: W. B. Mortenson, J. Kim.

Data analysis: W. B. Mortenson, J. Kim.

Drafting of manuscript: W. B. Mortenson, J. Kim.

Critical revision of manuscript for important intellectual content:

W. B. Mortenson, J. Kim.

Financial Disclosures: The authors have declared that no competing interests exist.

Funding/Support: The Canadian Institutes of Health Research open operating grant supported this work (grant number F15-00959).

\section{REFERENCES}

1. Brandt A, Iwarsson S, Ståhle A. Older people's use of powered wheelchairs for activity and participation. J Rehabil Med. 2004;36(2):70-77. [PMID:15180221] http://dx.doi.org/10.1080/16501970310017432

2. LaPlante MP, Kaye HS. Demographics and trends in wheeled mobility equipment use and accessibility in the community. Assist Technol. 2010;22(1):3-17, quiz 19.

[PMID:20402043] http://dx.doi.org/10.1080/10400430903501413

3. Statistics Canada. Participation and activity limitation survey 2006: A profile of assistive technology for people with dis- abilities [Internet]. 2008 [cited 2015 April 1]. Available from: http://www.statcan.gc.ca/pub/89-628-x/89-628-x2008005eng.htm

4. Kaye HS, Kang T, LaPlante MP. Mobility device use in the United States. Disability Statistics Report 14. Washington (DC): National Institute on Disability and Rehabilitation Research (US): 2000.60 p. Grant No.: H133B980045.

5. Australian Competition and Consumer Commission. Product Safety Australia [Internet]. Mobility scooter usage and safety survey report. 2012 Sept 4 [cited 2015 April 1]. Available from: https://www.productsafety.gov.au/content/ index.phtml/itemId/996221

6. Mortenson WB, Miller WC, Boily J, Steele B, Odell L, Crawford EM, Desharnais G. Perceptions of power mobility use and safety within residential facilities. Can J Occup Ther. 2005;72(3):142-52. [PMID:15988961] http://dx.doi.org/10.1177/000841740507200302

7. Mortenson WB, Miller WC. The wheelchair procurement process: Perspectives of clients and prescribers. Can J Occup Ther. 2008;75(3):167-75. [PMID:18615928] http://dx.doi.org/10.1177/000841740807500308

8. Canning B. Funding, ethics, and assistive technology: Should medical necessity be the criterion by which wheeled mobility equipment is justified? Top Stroke Rehabil. 2005;12(3):77-81. [PMID:16110430] http://dx.doi.org/10.1310/564P-FWK1-Q96Y-5AXJ

9. Arksey H, O’Malley L. Scoping studies: Towards a methodological framework. Int J Soc Res Methodol. 2005;e(1): 19-32. http://dx.doi.org/10.1080/1364557032000119616

10. Moher D, Liberati A, Tetzlaff J, Altman DG; PRISMA Group. Preferred reporting items for systematic reviews and meta-analyses: The PRISMA statement. BMJ. 2009; e(7716):332-336. [PMID:16110430] http://dx.doi.org/10.1371/journal.pmed.1000097

11. Krippendorf K. Content analysis: An introduction to its methodology. 2nd ed. Thousand Oaks (CA): Sage Publications; 2004.

12. Hubbard SL, Fitzgerald SG, Reker DM, Boninger ML, Cooper RA, Kazis LE. Demographic characteristics of veterans who received wheelchairs and scooters from Veterans Health Administration. J Rehabil Res Dev. 2006;43(7): 831-44. [PMID:17436170] http://dx.doi.org/10.1682/JRRD.2005.11.0174

13. Sullivan SJ, La Grow S, Alla S, Schneiders AG. Riding into the future: A snapshot of elderly mobility scooter riders and how they use their scooters. N Z Med J. 2014; 127(1402):43-49. [PMID:25228420]

14. Steyn PV, Chan AA. Mobility scooter research project [Internet]. Abbotsford (BC): University of the Fraser Valley, Centre for Education \& Research on Aging. 2008 Mar [cited 2015 April 1]. Available from: http://ufv.ca/media/ assets/centre-for-education--research-on-aging/ $\underline{\text { Scooter+report.pdf }}$ 
15. Blais D, Rutenberg U, Suen L. Mobility scooters for an ageing society [Internet]. TRANSED 2012: The 13th International Conference on Mobility and Transport for Elderly and Disabled People. 2012 [cited 2015 April 1]. Available from: http://www.transed2012.in/Common/Uploads/ Theme_J_Session_2/28-paper-transedAbstract00137.pdf

16. Brownsdon A, Marcar C. Scooter safe policy implications \& recommendations related to use of electric scooters and wheelchairs in the ACT [Internet]. Hughes (Australia): Council on the Ageing (ACT). 2002 Aug [cited 2015 April 1]. Available from: http://trove.nla.gov.au/work/34918350?selectedver$\underline{\text { sion }=\text { NBD42291821 }}$

17. Edwards K, McCluskey A. A survey of adult power wheelchair and scooter users. Disabil Rehabil Assist Technol. 2010;5(6):411-19. [PMID:20450455] http://dx.doi.org/10.3109/17483101003793412

18. Hubbard SL, Fitzgerald SG, Vogel B, Reker DM, Cooper RA, Boninger ML. Distribution and cost of wheelchairs and scooters provided by Veterans Health Administration. J Rehabil Res Dev. 2007;44(4):581-92. [PMID:18247255] http://dx.doi.org/10.1682/JRRD.2006.10.0136

19. Zagol BW, Krasuski RA. Effect of motorized scooters on quality of life and cardiovascular risk. Am J Cardiol. 2010; 105(5):672-76. [PMID:20185015] http://dx.doi.org/10.1016/j.amjcard.2009.10.049

20. Australian Competition and Consumer Commission. Product Safety Australia. [Internet]. Targeted study of injury data involving motorised mobility scooters, 2011. 2011 Mar 24 [cited on 2015 April 1]. Available from: http:// www.productsafety.gov.au/content/index.phtml/itemId/985925

21. Cassell E, Clapperton A. Consumer product-related injury (2): Injury related to the use of motorized mobility scooters [Internet]. Melbourne (Australia): Monash University, Accident Research Centre; 2006 [cited 2015 April 1]. Available from: http://www.monash.edu/ data/assets/ pdf_file/0005/218435/haz62.pdf

22. Murphy CG, Murphy IG, O’Rourke KS, O’Shea K. Motorised mobility scooters; upper limb fractures in elderly novice users. Clin Cases Miner Bone Metab. 2014; 11(2):132-35. [PMID:25285144]

23. Paparone P. Lower extremity ulceration caused by medical scooter injury: A case series. Geriatr Nurs. 2013;34(1):25-29. [PMID:22817776]

http://dx.doi.org/10.1016/j.gerinurse.2012.06.011

24. Hoenig H, Pieper C, Branch LG, Cohen HJ. Effect of motorized scooters on physical performance and mobility: A randomized clinical trial. Arch Phys Med Rehabil. 2007; 88(3):279-86. [PMID:17321817] http://dx.doi.org/10.1016/j.apmr.2006.11.022

25. Samuelsson K, Wressle E. Powered wheelchairs and scooters for outdoor mobility: A pilot study on costs and benefits. Disabil Rehabil Assist Technol. 2014;9(4):330-34.

\section{[PMID:23957388]}

http://dx.doi.org/10.3109/17483107.2013.827244

26. Sund T, Iwarsson S, Anttila H, Brandt Å. Effectiveness of powered mobility devices in enabling community mobilityrelated participation: A prospective study among people with mobility restrictions. PMR. 2015;7(8):859-70. [PMID:25677008]

27. Hagberg L, Hermansson L, Fredriksson C, Pettersson I. Cost-effectiveness of powered mobility devices for elderly people with disability. Disabil Rehabil Assist Technol. 2015; 1-6. [PMID:25634493] http://dx.doi.org/10.3109/17483107.2014.1002540

28. Löfqvist C, Pettersson C, Iwarsson S, Brandt A. Mobility and mobility-related participation outcomes of powered wheelchair and scooter interventions after 4-months and 1-year use. Disabil Rehabil Assist Technol. 2012;7(3):211-18. [PMID:21980966] http://dx.doi.org/10.3109/17483107.2011.619224

29. Sund T, Iwarsson S, Andersen MC, Brandt Å. Documentation of and satisfaction with the service delivery process of electric powered scooters among adult users in different national contexts. Disabil Rehabil Assist Technol. 2013; 8(2):151-60. [PMID:22804870] http://dx.doi.org/10.3109/17483107.2012.699584

30. Mortenson WB, Hoag E, Higgins R, Emery R, Joyce L. Stakeholders' perspectives related to the development of a scooter training program. Disabil Rehabil Assist Technol. 2016;11(4):289-94. [PMID:25170986] http://dx.doi.org/10.3109/17483107.2014.951975

31. Jannink MJ, Erren-Wolters CV, de Kort AC, van der Kooij $\mathrm{H}$. An electric scooter simulation program for training the driving skills of stroke patients with mobility problems: A pilot study. Cyberpsychol Behav. 2008;11(6):751-54. [PMID:18954289] http://dx.doi.org/10.1089/cpb.2007.0271

32. Niv A, Weiss P, Ratzon N. The effectiveness of combining occupational therapy intervention with computerized training for improved driving on the electric scooter. Israeli $\mathrm{J}$ Occup Ther. 2008;18(1):E14-15.

33. Nitz JC. Evidence from a cohort of able bodied adults to support the need for driver training for motorized scooters before community participation. Patient Educ Couns. 2008; 70(2):276-80. [PMID:18065187] http://dx.doi.org/10.1016/j.pec.2007.10.014

34. Fomiatti R, Moir L, Richmond J, Millsteed J. The experience of being a motorised mobility scooter user. Disabil Rehabil Assist Technol. 2014;9(3):183-87. [PMID:23802129] http://dx.doi.org/10.3109/17483107.2013.814171

35. May E, Garrett R, Ballantyne A. Being mobile: Electric mobility-scooters and their use by older people. Ageing 
Soc. 2010;30(7):1219-37.

http://dx.doi.org/10.1017/S0144686X10000334

36. Jörg F, Boeije HR, Schrijvers AJ. Professionals assessing clients' needs and eligibility for electric scooters in the Netherlands: Both gatekeepers and clients advocates. $\mathrm{Br}$ J Soc Work. 2005;35(6):823-42. http://dx.doi.org/10.1093/bjsw/bch279

37. Maywald A, Stanley M. Prescribing mobility scooters in Australia: Occupational therapists' narratives. Aust Occup Ther J. 2015;62(2):86-92. [PMID:24825351] http://dx.doi.org/10.1111/1440-1630.12131

38. King EC, Dutta T, Gorski SM, Holliday PJ, Fernie GR. Design of built environments to accommodate mobility scooter users: Part II. Disabil Rehabil Assist Technol. 2011;6(5):432-39. [PMID:21657823]

http://dx.doi.org/10.3109/17483107.2010.549898

39. Dutta T, King EC, Holliday PJ, Gorski SM, Fernie GR. Design of built environments to accommodate mobility scooter users: Part I. Disabil Rehabil Assist Technol. 2011; 6(1):67-76. [PMID:20690862] http://dx.doi.org/10.3109/17483107.2010.509885

40. Souza AE, Pearlman JL, Cooper R, Kelleher A, Gebrosky B, Cooper RA. Evaluation of scooters using ANSI/RESNA standards. J Rehabil Res Dev. 2013;50(7):1017-34. [PMID:24301438] http://dx.doi.org/10.1682/JRRD.2011.03.0054

41. Lukersmith S, Radbron L, Hopman K. Development of clinical guidelines for the prescription of a seated wheelchair or mobility scooter for people with traumatic brain injury or spinal cord injury. Aust Occup Ther J. 2013; 60(6):378-86. [PMID:24299477] http://dx.doi.org/10.1111/1440-1630.12077

42. Kloosterman MG, Snoek GJ, van der Woude LH, Buurke $\mathrm{JH}$, Rietman JS. A systematic review on the pros and cons of using a pushrim-activated power-assisted wheelchair. Clin Rehabil. 2013;27(4):299-313. [PMID:22952307] http://dx.doi.org/10.1177/0269215512456387

43. Church RL, Marston JR. Measuring accessibility for people with a disability. Geogr Anal. 2003;35(1):83-96. http://dx.doi.org/10.1353/geo.2002.0029

44. Berg K, Hines M, Allen S. Wheelchair users at home: Few home modifications and many injurious falls. Am J Public
Health. 2002;92(1):48. [PMID:11772759]

http://dx.doi.org/10.2105/AJPH.92.1.48

45. Kirby RL, Ackroyd-Stolarz SA, Brown MG, Kirkland SA, MacLeod DA. Wheelchair-related accidents caused by tips and falls among noninstitutionalized users of manually propelled wheelchairs in Nova Scotia. Am J Phys Med Rehabil. 1994;73(5):319-30. [PMID:7917161] http://dx.doi.org/10.1097/00002060-199409000-00004

46. Nelson AL, Groer S, Palacios P, Mitchell D, Sabharwal S, Kirby RL, Gavin-Dreschnack D, Powell-Cope G. Wheelchair-related falls in veterans with spinal cord injury residing in the community: A prospective cohort study. Arch Phys Med Rehabil. 2010;91(8):1166-73.

[PMID:20684896] http://dx.doi.org/10.1016/j.apmr.2010.05.008

47. Karmarkar AM, Collins DM, Wichman T, Franklin A, Fitzgerald SG, Dicianno BE, Pasquina PF, Cooper RA. Prosthesis and wheelchair use in veterans with lower-limb amputation. J Rehabil Res Dev. 2009;46(5):567-76. [PMID:19882491] http://dx.doi.org/10.1682/JRRD.2008.08.0102

48. Salatin B, Rice I, Teodorski E, Ding D, Cooper RA. A survey of outdoor electric powered wheelchair driving [Abstract]. 33rd RESNA International Conference; 2010 June 26-30; Las Vegas, Nevada: RESNA.

Submitted for publication May 15, 2015. Accepted in revised form November 3, 2015.

This article and any supplementary material should be cited as follows:

Mortenson WB, Kim J. Scoping review of mobility scooter-related research studies. J Rehabil Res Dev. 2016; 53(5):531-40.

http://dx.doi.org/10.1682/JRRD.2015.05.0084

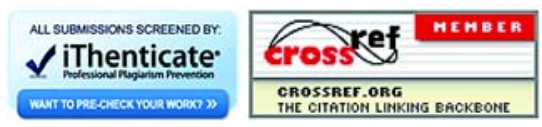


